\title{
O outro lado do paraíso: novos dados e reflexões sobre violência entre pescadores-coletores pré-coloniais
}

LESSA, A.; SCHERER, L.Z. O outro lado do paraíso: novos dados e reflexões sobre violência entre pescadores-coletores pré-coloniais. Revista do Museu de Arqueologia e Etnologia, São Paulo, 18: 89-100, 2008.

Resumo: São raros os estudos sobre traumas agudos e violência entre grupos pré-coloniais litorâneos brasileiros. Dificuldades devido a fatores tafonômicos e metodológicos, além da inexistência de dados iconográficos, são as principais causas da escassez de pesquisas sobre o tema. Diante deste cenário, este artigo vem contribuir com novos dados sobre violência entre pescadores-coletores do sul, apontando para um aumento dos episódios de agressão em relação ao período de ocupação da costa pelos construtores de sambaquis. Finalmente, é proposto o desenvolvimento de novas abordagens para o entendimento deste fenômeno, conjugando-se eventos climáticos e contextos sócio-econômicos específicos.

Palavras-chave: Traumas agudos - Violência - Populações costeiras - Eventos climáticos.

\section{Introdução}

C interesse sobre as questões relacionadas a violência em sociedades pré-coloniais ganhou impulso durante a década de 90, principalmente entre pesquisadores norteamericanos das áreas de bioarqueologia e antropologia, os quais multiplicaram os volumes

${ }^{*}$ ) Dedicamos esta pesquisa à memória de João Alfredo Rohr, no centenário de seu nascimento. Que seu amor pela pesquisa e que sua incansável luta pela preservação dos sítios arqueológicos continuem sendo um exemplo para muitas gerações de arqueólogos. $\left({ }^{* *}\right)$ Escola Nacional de Saúde Pública/Fiocruz <lessa@ensp.fiocruz.br>

$\left({ }^{* * *}\right)$ Universidade Federal de Santa Catarina <uscherer@gmail.com> dedicados exclusivamente ao tema (ex. Keeley 1996; Wrangham e Peterson 1996; Martin e Frayer 1997; Le Blanc 2003; Otterbein 2004; Pearson e Thorpe 2005; Fry 2005). Este interesse vem acompanhando uma tendência mundial de preocupação com a sua crescente emergência, mesmo em países ricos, tendo orientado também pesquisas na área da saúde.

Embora seja relativamente recente a ênfase dada às questões que envolvem a violência, sua manifestação é um fenômeno que acompanha o homem desde o alvorecer da espécie, parecendo constituir-se um elemento inerente à vida em sociedade. E é justamente nesse ponto que antropólogos e arqueólogos, em especial os bioarqueólogos, têm contribuído para os estudos sobre a agressividade humana (Lessa 2004). 
O outro lado do paraíso: novos dados e reflexões sobre violência entre pescadores-coletores pré-coloniais. Revista do Museu de Arqueologia e Etnologia, São Paulo, 18: 89-100, 2008.

Apesar do potencial informativo representado pelo tema, ainda são escassos os estudos específicos sobre traumas agudos associados à violência em séries esqueléticas brasileiras. Uma primeira abordagem foi realizada por Lessa e Medeiros (2001) para populações construtoras de sambaquis, e por Lessa (2005) para grupos pescadores-coletores.

É possível que o pouco interesse dos bioarqueólogos brasileiros sobre o tema esteja associado ao estado de conservação inadequado e conseqüente baixa representatividade das séries, fatores que acabam por tornar os dados relativos a agressões físicas pouco consistentes. Buscando-se contornar este obstáculo, uma metodologia com base na agregação das séries segundo parâmetros regionais foi proposta por Rodrigues-Carvalho et al. (no prelo), embora esta abordagem certamente mascare aspectos próprios de cada grupo, contemplando apenas a elaboração de um quadro muito geral sobre a questão.

Outra dificuldade observada nos estudos sobre violência em material esquelético diz respeito ao diagnóstico das lesões traumáticas, o que torna difícil, algumas vezes, sua associação com episódios de agressão. Muitos autores têm realizado os diagnósticos de forma um tanto simplista e equivocada, especificamente no que se refere às pequenas depressões no crânio, com superfície irregular e sem um padrão morfológico ou de localização específico, as quais podem estar associadas a processos não traumáticos, sendo necessário um exame radiológico para a comprovação do diagnóstico.

Outro diagnóstico problemático refere-se às tão mencionadas fraturas nas epífises distais das ulnas, denominadas "parry fractures" por estarem associadas à defesa de um golpe, cujo diagnóstico muitas vezes não leva em consideração a localização e o tipo de fratura, assim como a direção da força incidente. Fraturas espiraladas e fraturas oblíquas, por exemplo, dificilmente podem ser associadas a traumas diretos, uma vez que resultam de uma pronação forçada do membro, como acontece durante uma queda (Lovell 1997). As fraturas transversas, por sua vez, embora possam ser facilmente associadas a traumas diretos, também podem ter sua etiologia relacio- nada a um estresse repetitivo (Kitchin e Lancaster 1948; Orava et al. 1978; Tanabe et al. 1991).

Com relação aos grupos pré-coloniais litorâneos ${ }^{1}$ especificamente, pode-se adicionar a estas dificuldades diagnósticas o fato de não existirem dados iconográficos, ou ainda, tal como existente para grupos do período de contato com os Europeus, dados etnohistóricos que informem sobre estratégias de combate ou sobre rituais violentos. A inexistência destes dados inviabiliza a associação de outros tipos de lesão com episódios de agressão, como as fraturas no tórax (Lovell 1997; Lessa e Mendonça de Souza 2004), nos metacarpos (Robb 1997) e nos ossos nasais (Walker 1997; Lessa e Mendonça de Souza 2006), satisfatoriamente caracterizados em outras séries arqueológicas. O mesmo ocorre com dados que informem sobre as armas utilizadas por estes grupos, as quais, quando confeccionadas com materiais perecíveis, desaparecem do registro arqueológico.

(1) Serão mencionados ao longo do texto distintos tipos de grupos pré-coloniais litorâneos. Prous e Piazza (1977) definiram sambaquis como sítios arqueológicos (ou a porção de sítios, quando com sobreposição), nos quais os vestígios culturais seriam parte de um espesso sedimento detrítico e cuja totalidade, ou lentes, seriam formadas em mais de $3 / 4$ partes por conchas de moluscos terrestres ou aquáticos. Outros tipos de sítio presentes no litoral brasileiro foram denominados por Rohr (1977) como jazidas paleoetnográficas ou sítios rasos. Ainda segundo a descrição deste autor, "Ocorre na Ilha [de Santa Catarina] uma série de sítios arqueológicos rasos, com numerosos sepultamentos e uma cultura material muito copiosa, semelhante à cultura dos sambaquis. No entanto, estes sítios não são sambaquis porque encerram teor muito baixo de conchas. A camada arqueológica dos mesmos, de aproximadamente um metro de espessura, assenta sobre areia da praia, sendo formada por húmus escuro, de mistura com areia, carvão vegetal, ossadas de peixes, aves e mamíferos e conchas esparsas" (p. 8). ..."Quando não existiam moluscos suficientes para abastecerem a sua mesa, passavam a dedicar-se à pesca, o que é atestado pelo elevado teor de ossadas de peixes, que aparecem naquele tipo de sítios arqueológicos" (p. 10). Por este motivo, os grupos que habitavam os sítios rasos são denominados pescadores-coletores. Ainda segundo Rohr (1977: 8-9), são sítios rasos os da Base Aérea, Tapera, Cabeçudas, a camada mais antiga do Pântano do Sul, e Armação do Sul (os sítios grifados são mencionados no 
Pelo exposto, até o momento as lesões causadas pela penetração de pontas de projétil parecem ser as mais seguras para se inferir violência entre os grupos litorâneos. Embora a literatura apresente referências pouco precisas sobre pontas localizadas durante as escavações entre as costelas de indivíduos (Kneip 1987; 1994), sua presença, ou de esquírolas, encravadas nos ossos são marcadores indiscutíveis de conflitos.

Achados deste tipo, no entanto, são raros, principalmente porque, com algumas exceções como as referências de Kneip; Rohr (1996) e Schmitz et al. (1992), os arqueólogos não têm se preocupado em inferir e documentar de forma minuciosa a presença de pontas dentro da caixa torácica ou do espaço pélvico, sendo as mesmas sempre interpretadas como acompanhamento funerário. Desta forma, apenas as pontas efetivamente encravadas nos ossos têm sido objeto de interesse por parte dos pesquisadores.

Diante da importância destes achados perante o contexto acima mencionado, o

texto). Laranjeiras II foi classificado da mesma forma por Schmitz et al. (1993). As poucas datações disponíveis sugerem que os sítios rasos sem cerâmica - camada mais antiga de Pântano do Sul = 4.500 A.P. (Rohr 1977); e início da ocupação do Armação do Sul $=2.670$ \pm 90 A.P (Schmitz et al. 1992) - são mais antigos do que aqueles com cerâmica, embora o momento de ocupação mais recente do Armação do sul possa estar situado em torno do ano 1.000 A.D., tal como discutido no texto. As datações disponíveis para os sítios rasos com cerâmica, sempre da Tradição Itararé, são de $810 \pm 180 \mathrm{AD}$ e $920 \pm 180 \mathrm{AD}$ para Praia da Tapera e $1150 \pm 70 \mathrm{AD}$ para Base Aérea. Em outro sítio raso mencionado no presente texto, a segunda camada de ocupação do sítio Enseada I, foi descrita por Beck (1972) como estando relacionada a uma população cuja alimentação estaria centrada na pesca, embora haja grande quantidade de mamíferos terrestres, e que produzia cerâmica, posteriormente classificada como pertencente à Tradição Itararé. Não existe datação disponível para este sítio. A autora reforça a diferença entre esta segunda camada de ocupação do sítio e a camada mais antiga, a qual representa um típico sambaqui caracterizado pela presença de instrumental ósseo especializado e predominância de conchas de molusco. Finalmente, Bandeira (2004) identifica uma situação semelhante para a segunda camada de ocupação do sítio Itacoara, cuja cerâmica também foi classificada como Itararé. objetivo deste trabalho é apresentar o único caso conhecido até o momento de indivíduo atingido por ponta de projétil entre grupos pescadorescoletores sem cerâmica, assim como novos dados sobre violência entre pescadores-coletores ceramistas, além de discutir alguns aspectos relacionados à conduta agressiva entre populações litorâneas.

\section{Dados sobre violência para sítios de pescado- res-coletores sem cerâmica}

\section{Descrição da lesão causada pela penetração de ponta de projétil}

O achado ocorreu em 2007 durante uma análise superficial da série esquelética proveniente do sítio raso Armação do Sul, localizado na praia homônima em Florianópolis (SC). A série não foi investigada em detalhe uma vez que não passou por trabalho de curadoria, estando ainda recoberta com o sedimento de campo. Trata-se de um indivíduo masculino adulto cuja quarta vértebra lombar apresenta uma ponta de projétil confeccionada sobre diáfise de osso alojada dentro do corpo vertebral, sem sinais de cicatrização ao redor da lesão (Figs. 1, 2 e 3). A partir da imagem radiológica da vértebra, foi possível uma melhor compreensão do evento. A trajetória de penetração da ponta foi anterior, no meio do corpo vertebral, tendo a extremidade distal da mesma penetrado alguns milímetros no processo espinhoso. Através do orifício de entrada, é possível observar a porção proximal do projétil no ponto onde o mesmo se quebrou provavelmente durante uma tentativa de retirá-la do corpo da vítima. Não é possível, portanto, determinar se a ponta é simples ou dupla. Dentro do corpo vertebral observa-se a porção central da ponta, cuja extremidade fragmentada desponta posteriormente para fora do corpo vertebral, além de parte de sua porção distal. Através do orifício de saída da ponta é possível observar, além da extremidade fragmentada, sua extremidade distal.

Após a penetração da ponta no corpo da vítima, uma tentativa por parte do agressor de fazê-la penetrar mais fundo causou a sua quebra 
O outro lado do paraíso: novos dados e reflexões sobre violência entre pescadores-coletores pré-coloniais. Revista do Museu de Arqueologia e Etnologia, São Paulo, 18: 89-100, 2008.

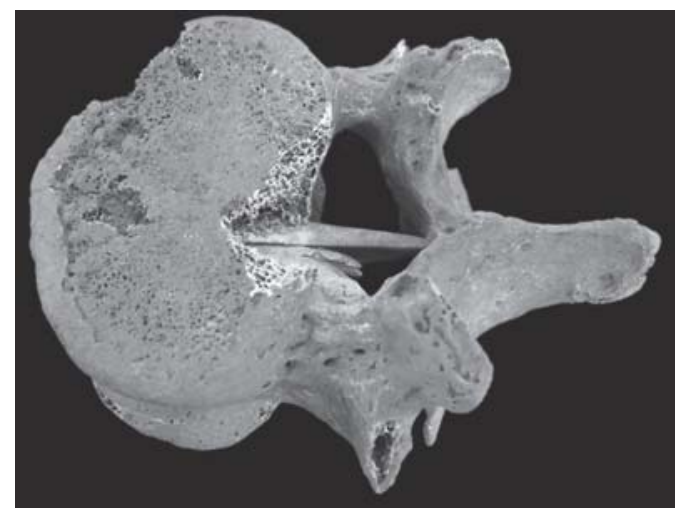

Fig. 1. Quarta vértebra lombar com ponta óssea no interior do corpo, vista superior. Note-se a extremidade distal e a extremidade fragmentada da ponta óssea despontando posteriormente para fora do corpo vertebral. Indivíduo adulto masculino - Sítio Armação do Sul (SC).

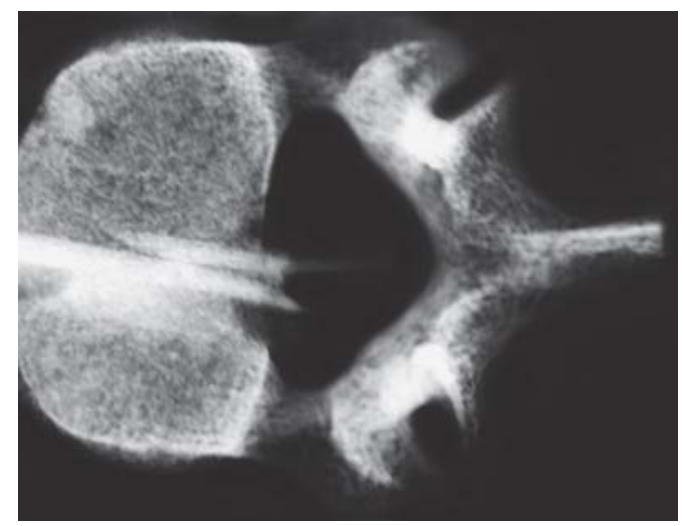

Fig. 3. Radiografia da quarta vértebra lombar com ponta óssea no interior do corpo, vista superior. Pode ser observada a porção central da ponta óssea, além de parte de sua porção distal. Indivíduo adulto masculino - Sítio Armação do Sul (SC).

dentro do corpo vertebral. Apenas a continuação de uma força ativa incidindo sobre a ponta óssea, com ligeiro desvio de angulação, forçandoa em direção ao obstáculo representado pela vértebra, causaria a sua quebra dentro da mesma.

A angulação totalmente horizontal $\left(90^{\circ}\right)$ da ponta em relação à quarta vértebra lombar sugere que o ataque ocorreu a uma pequena distância entre a vítima e o agressor. A grande força necessária para a sua penetração e quebra dentro do osso, permite supor que se tratava de uma

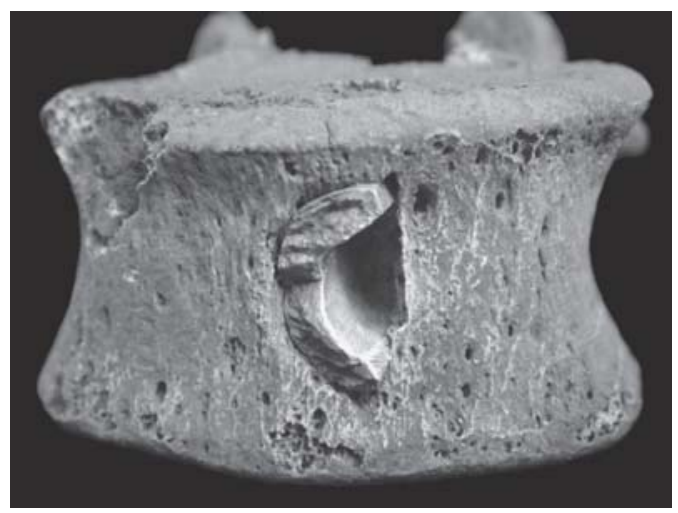

Fig. 2. Quarta vértebra lombar com ponta óssea no interior do corpo, vista anterior. Indivíduo adulto masculino. Note-se o orifício de entrada da ponta óssea, onde pode ser observada a porção proximal do projétil no ponto onde foi quebrada. Indivíduo adulto masculino - Sítio Armação do Sul (SC).

lança, a qual foi arremetida contra a vítima enquanto esta se encontrava deitada de costas, situação em que o agressor poderia utilizar a força de ambas as mãos e do tórax para o desferimento do golpe, com a vértebra e o próprio solo atuando como forças de resistência. Caso a vítima estivesse de pé durante a segunda arremetida, o ângulo do braço do agressor para empunhadura e estocada da lança lhe forneceria uma força consideravelmente menor, e tampouco haveria força de resistência suficiente para quebrar a ponta óssea dentro do corpo vertebral.

Mais uma vez em função dos escassos dados sobre lesões associadas a flechadas, vale citar também a descrição de Schmitz et al. (1992: 131) de um esqueleto de criança proveniente do mesmo sítio, o qual apresentou uma ponta óssea dentro do tórax. Embora neste caso sua descrição seja pouco precisa, uma avaliação do conteúdo material das estruturas funerárias permitiu atestar que, das 15 crianças recuperadas no sítio Armação do Sul, ${ }^{2}$ nenhuma apresentava ponta de

(2) Das 15 crianças mencionadas, apenas uma foi sepultada junto a um indivíduo adulto (\# 34 e 34A). São os únicos sepultamentos suspeitos de serem secundários. Junto aos esqueletos havia pontas ósseas, as quais, caso estivessem efetivamente associadas a esta estrutura funerária, provavelmente pertenciam ao indivíduo adulto. 
projétil como acompanhamento funerário. Este dado reforça a inferência de que esta criança tenha vivenciado um episódio de violência.

\section{Contextualização}

Os dados das escavações, assim como interpretações relacionadas ao assentamento e seus habitantes foram publicados por Schmitz et al. (1992).

O sítio raso pré-cerâmico de pescadorescoletores da Armação do Sul foi escavado por João Alfredo Rohr em duas etapas, em 1969 e 1974, quando foram registrados 86 sepultamentos em uma área de $270 \mathrm{~m}^{2}$. A estimativa da extensão total do sítio é de aproximadamente $600 \mathrm{~m}^{2}$. Muitos sepultamentos não foram recuperados devido ao péssimo estado de conservação, ou porque se encontravam abaixo dos pilares da antiga Armação das Baleias ou dos muros e da casa do proprietário do terreno.

Foram identificados dois momentos distintos de ocupação pré-colonial: a) um mais recente, com a deposição na camada de terra preta e distribuição dos 19 sepultamentos em uma área mais restrita. Tanto o indivíduo adulto flechado ( $7,1 \%$ dos adultos) quanto a criança com ponta óssea dentro da caixa torácica estão localizados neste momento de ocupação; b) e um antigo, com a deposição nas camadas de areia subjacentes e distribuição dos demais sepultamentos em toda a extensão da escavação. Uma amostra de carvão, correspondente ao início da ocupação do sítio, foi datada em $2.670 \pm 90$ anos A.P. (I-9212) (Schmitz et al. 1992).

As estruturas e acompanhamentos funerários apresentam diferença acentuada entre os dois momentos de ocupação. A população mais antiga recebeu um tratamento mais cuidadoso, tendo os mortos sido envolvidos em pigmento vermelho, e enterrados com uma grande quantidade de oferendas variadas, com exceção das pontas ósseas, que não os acompanhavam. A população mais recente não apresentava pigmento vermelho sobre os ossos, e os acompanhamentos tornaram-se escassos, apesar da presença de um elemento novo, as pontas ósseas.
Neste contexto, chama a atenção um indivíduo masculino (\#29), localizado estratigraficamente na transição entre os sepultamentos antigos e recentes, o qual apresentou rico pacote de oferendas que inclui, entre outros itens, 50 pontas ósseas junto da cabeça e o único artefato de ametista encontrado no sítio. Schmitz et al. (1992) interpretaram as mudanças no padrão funerário e o contexto associado a este indivíduo como um possível aumento de violência durante o momento mais recente de ocupação do sítio, e valorização de chefes guerreiros. Ainda segundo os autores, esta última ocupação poderia coincidir com a movimentação de populações ao longo do litoral por volta do final do primeiro milênio da era Cristã, ou do planalto para o litoral, como sugere Neves (1984).

Esta hipótese de aumento de violência ganha força diante do indivíduo flechado aqui descrito, além de dar ainda mais suporte à inferência de episódio de conflito envolvendo a criança com ponta óssea dentro da caixa torácica, descrita por Rohr. Estes são até o momento os únicos dados disponíveis sobre violência para populações de pescadores-coletores sem cerâmica. Lessa (2005) e Rodrigues-Carvalho et al. (no prelo) já haviam proposto uma hipótese preliminar sobre esta questão para populações pescadoras-coletoras ceramistas, e os dados aqui apresentados possibilitam novas reflexões sobre o tema.

\section{Dados sobre violência para sítios de pescadores-coletores com cerâmica}

Os dados apresentados a seguir têm ainda um caráter preliminar em função do estado de conservação inadequado das séries para a análise de traumas agudos, e conseqüente baixa representatividade quantitativa, com exceção do sítio Praia da Tapera. Os dados relativos ao sítio Base Aérea (Florianópolis/ SC) são inéditos, os demais se referem a pesquisas anteriores da primeira autora e de outros autores: Tapera (Lessa 2005); 
O outro lado do paraíso: novos dados e reflexões sobre violência entre pescadores-coletores pré-coloniais. Revista do Museu de Arqueologia e Etnologia, São Paulo, 18: 89-100, 2008.

Itacoara ${ }^{3}$ - camada superior (Tiburtius et al. 1950/51; Bandeira 2004; Rogrigues-Carvalho et al., no prelo) e Enseada I - camada superior (Rodrigues-Carvalho et al., no prelo).

Considerando-se o total da amostra analisada, o percentual de lesões é de $13,2 \%$. A segmentação dos dados por sexo demonstra que os homens apresentam mais que o dobro do percentual de lesões $(17,8 \%)$ em relação às mulheres (7,1\%). A série que apresenta os maiores percentuais entre os homens é Itacoara (27,3\%), e entre as mulheres é Base Aérea (25\%) (Tabela 1). Esses valores, no entanto, devem ser relativizados e entendidos como uma primeira aproximação ao tema em função de possíveis vieses relacionados às questões acima mencionadas.

As lesões aqui consideradas foram as perfurações por pontas de projétil, além das fraturas nas epífises distais das ulnas e as fraturas em depressão nos crânio, sempre que os elementos diagnósticos, examinados segundo a metodologia anteriormente descrita, permitiram tais inferências.

\section{Discussão}

A hipótese de Schmitz et al. (1992) de que a ocupação mais recente, pré-cerâmica, do sítio Armação do Sul possa ter ocorrido por volta do ano 1000 , destaca-se como elemento importante na discussão geral sobre a questão da violência entre grupos litorâneos, embora as poucas datações obtidas para sítios de pescadores-coletores sejam inconsistentes para se estabelecer de forma segura o início de sua ocupação do litoral.

(3) Tiburtius et al. (1950/51: 343) fazem referência a dois indivíduos atingidos por pontas ósseas: um adulto, com ponta de flecha espetada no ilíaco, e uma criança, sepultada ao lado do primeiro, com ponta de flecha espetada no crânio. Na quantificação apresentada na Tabela 1, foram incluídos apenas os indivíduos adultos. Bandeira (2004) fez referência a um indivíduo adulto masculino com ponta óssea espetada em um corpo vertebral. Rodrigues-Carvalho et al. (no prelo) analisaram a série coletada por Tiburtius disponível no MASJ, composta quase exclusivamente por crânios. Foram analisados 11 crânios masculinos (um com lesão) e 8 femininos (um com lesão).
Em apoio a esta hipótese, pode ser citado o próprio contexto arqueológico do sítio, o qual demonstra uma série de aspectos em comum com os assentamentos de pescadores-coletores ceramistas. Neste sentido, o elemento que mais chama a atenção é o refugo alimentar, o qual, embora seja predominantemente marinho, apresenta grande variedade de espécies e inclui a caça terrestre presente nas matas fechadas; a caracterização da sua indústria lítica pelo retalhamento bipolar de seixos, produzindo artefatos típicos, o distingue dos demais sítios pré-cerâmicos, assemelhando-se aos sítios de pescadores-coletores com cerâmica do Rio Lessa e Enseada I; a mesma variedade de artefatos fusiformes do Armação do Sul existe também nos sítios de pescadores-coletores com cerâmica de Praia da Tapera e Laranjeiras II; e embora a maior parte dos sepultamentos pareça individualizada, percebem-se agrupamentos que poderiam indicar o início de cemitérios domiciliares, tal como observados na Tapera, Laranjeiras II e Cabeçudas.

Admitindo-se, portanto, que esteja correta a estimativa cronológica da ocupação mais recente do Armação do Sul, ela seria contemporânea, dentro de um intervalo de tempo amplo, de sítios de pescadores-coletores com cerâmica que apresentam prevalências significativas de marcas de violência, tais como Praia da Tapera, com datações de $810 \pm 180 \mathrm{AD}$ e $920 \pm 180 \mathrm{AD}$ (Rohr 1966; Silva et al. 1990), Base Aérea, com datação de $1150 \pm 70 \mathrm{AD}$ (Schmitz et al. 1993) e segunda ocupação do Itacoara, com datação de $1250 \pm 30$ AP (datação inédita ${ }^{4}$ )

Por volta deste período, o modo de vida sambaquieiro já teria entrado em declínio, uma vez que são raras as datações para estes sítios que ultrapassam os primeiros séculos do primeiro milênio. $^{5}$

(4) Pesquisadora responsável pela datação: Dra Ândrea Kely dos Santos - Laboratório de Paleogenética/UFPA. Laboratório responsável pela datação: Geochron Laboratories-USA. Número da amostra: GX-32804. MAS. Datação: $1250 \pm 30^{14} \mathrm{C}$ years BP $\left({ }^{13} \mathrm{C}\right.$ corrected $)$. ${ }^{\mathrm{d} 13} \mathrm{C}_{\mathrm{PDB}}=-20.6 \%$.

(5) Para listas de datações de sítios litorâneos consultar Andrade Lima (1999/2000) e Gaspar (1998). 
Tabela 1

\begin{tabular}{|c|c|c|c|c|c|c|c|c|c|}
\hline \multicolumn{10}{|c|}{$\begin{array}{l}\text { Freqüência de indivíduos que apresentam lesões associadas à violência entre grupos } \\
\text { pescadores-coletores ceramistas pré-coloniais }\end{array}$} \\
\hline \multirow{2}{*}{ Sítios } & \multicolumn{3}{|c|}{ Masculinos } & \multicolumn{3}{|c|}{ Femininos } & \multicolumn{3}{|c|}{ Total } \\
\hline & $\mathrm{N}$ & A & $\%$ & $\mathrm{~N}$ & A & $\%$ & $\mathrm{~N}$ & A & $\%$ \\
\hline Tapera & 29 & 5 & 17,2 & 26 & 1 & 3,8 & 55 & 5 & 10,9 \\
\hline Base Aérea & 11 & 1 & 9 & 4 & 1 & 25 & 15 & 2 & 13,3 \\
\hline Itacoara & 11 & 3 & 27,3 & 8 & 1 & 12,5 & 19 & 4 & 21 \\
\hline Enseada I & 5 & 1 & 20 & 4 & - & - & 9 & 1 & 11,1 \\
\hline Total & 56 & 10 & 17,8 & 42 & 3 & 7,1 & 98 & 13 & 13,2 \\
\hline
\end{tabular}

$\mathrm{N}$ = número de indivíduos analisados

$\mathrm{A}=$ número de indivíduos atingidos

Tal como proposto por Schmitz et al. (1992) para o sítio Armação do Sul, estudos preliminares focalizando especificamente a questão da violência, além dos novos dados aqui apresentados, apontam para um aumento significativo do comportamento agressivo ao longo do tempo. A comparação entre os dados associados ao período de construção dos sambaquis, com prevalência de 3\% para as lesões (Lessa e Medeiros 2001), e os dados associados ao período posterior, quando o litoral foi habitado pelos grupos pescadores-coletores ceramistas, com prevalência de $13,2 \%$ para as lesões, demonstra uma tendência à emergência de situações de tensão social no litoral.

Lessa (2005), ao investigar os traumas agudos na série proveniente do sítio Praia da Tapera, propôs tanto interpretações mais particulares para este fenômeno, considerando as especificidades do sítio, quanto interpretações em nível mais geral. Sob esta última perspectiva, dois aspectos que separam as populações construtoras de sambaquis e as populações ceramistas que ocuparam as aldeias litorâneas foram considerados. Estes aspectos certamente se associam à diferença temporal entre as ocupações nos dois tipos de sítios, considerandose que os sambaquis foram ocupados entre aproximadamente 6.000 anos atrás e o primeiro milênio da era cristã, e as aldeias litorâneas de grupos ceramistas correspondem a ocupações a partir do final do primeiro milênio.

Um deles diz respeito à ideologia subjacente à atividade construtiva dos montes de conchas, uma vez que eles não teriam sido feitos de forma aleatória, mas certamente obedeceram a um projeto ideologicamente determinado (Gaspar 1992; Andrade Lima 1999/2000). É fato que esta ideologia confere certa unidade às populações construtoras de sambaquis, ainda que não se pretenda aqui ignorar deliberadamente as variações inerentes aos sub-sistemas que as compõem. Questões de caráter êmico, relacionadas a esse substrato ideológico, podem ter forjado um comportamento pouco agressivo a partir do desenvolvimento de outros mecanismos para resolução de conflitos. Paralelamente à falência do sistema sambaquiano e surgimento de uma nova ordem, onde já não importavam as premissas associadas à acumulação de conchas e observase a introdução de uma importante inovação tecnológica como a cerâmica, é possível que a agressividade tenha adquirido uma nova dimensão e importância entre as populações litorâneas.

O segundo aspecto está relacionado a uma mudança no padrão de subsistência entre os dois tipos de sítios, ${ }^{6}$ passando de uma exploração intensa dos frutos do mar em geral, principalmente moluscos e peixes (Lima 1991; Bandeira 1992; Figuti 1993; Figuti e Klökler 1996) e ausência ou raridade de fauna terrestre (Prous 1992), para uma maior diversificação

(6) A discussão completa sobre a associação entre mudança no padrão de subsistência e aumento da violência pode ser consultada em Lessa (2005: 203 204). Para uma discussão específica sobre a questão entre construtores de sambaquis, consultar Lessa e Medeiros (2001). 
O outro lado do paraíso: novos dados e reflexões sobre violência entre pescadores-coletores pré-coloniais. Revista do Museu de Arqueologia e Etnologia, São Paulo, 18: 89-100, 2008.

alimentar que inclui, além da pesca, a caça de um grande número de mamíferos terrestres e aquáticos, o que se reflete na proliferação das pontas ósseas (Beck 1972; Tiburtius et al. 1950/51; Silva et al. 1990; Bandeira 1992; Schmitz et al. 1993; Schmitz 1996). Algumas hipóteses têm sido aventadas para a mudança no padrão de subsistência dessas populações, como a de uma diminuição na oferta de alimentos marinhos em função das oscilações do nível do mar (Hurt 1974; Tenório 1995), ou ainda o esgotamento das colônias de moluscos provocado por um sistema altamente predatório e imprevidente de coleta (Lima 1999/2000).

Os novos dados aqui apresentados, no entanto, também apontam para um aumento de violência entre outros grupos pescadorescoletores, sem cerâmica, mas possivelmente contemporâneos aos ceramistas, o que nos obriga a uma reflexão sobre possíveis aspectos mais abrangentes para o fenômeno. Esta convergência dos dados sobre violência para um período próximo ao ano mil pode estar assinalando um fenômeno muito mais amplo do que o esgotamento das colônias de moluscos que abasteciam cada sambaqui, e ainda mais impactante do que a oscilação do nível do mar.

Neste sentido, pesquisas na área de paleoclimatologia realizadas em diferentes partes do globo com base em análises sedimentológicas, de dendrocronologia, pólen, e de vestígios de incêndios durante o Holoceno tardio têm comprovado a ocorrência de um fenômeno climático conhecido como Medieval Climate Anomaly - MCA. ${ }^{7}$ Durante o atual período interglacial (i.e., os últimos 11.000 anos ou Holoceno), as temperaturas em todo o globo diminuíram gradualmente a partir de uma média máxima $\left(2^{\circ} \mathrm{C}\right.$ mais quente do que a temperatura atual), alcançada durante o Holoceno inicial, por volta de 9.000 anos atrás. Dentro desta tendência ao resfriamento da temperatura global, ocorreram pequenos períodos de temperaturas anôma-

(7) Tanto a denominação do fenômeno quanto do período a ele relacionado se devem ao fato de os primeiros estudos sobre o tema terem focalizado especificamente a Europa Ocidental. las, mais quentes. Entre aproximadamente 900 $\mathrm{AD}$ e $1350 \mathrm{AD}$, foram registradas temperaturas bem mais elevadas e períodos de seca regionais em diferentes regiões do mundo, se comparados com os períodos anterior e posterior. Tanto sob o aspecto ambiental quanto cultural, foram registradas respostas a este período, denominado Medieval Warm Period (Millar e Woolfenden 1999; Soon et al. 2003).

Com relação ao continente americano especificamente, a América do Norte apresenta inúmeros estudos paleoclimáticos, com base em diferentes metodologias, os quais identificam o fenômeno MCA, ou identificam a ocorrência de temperaturas mais altas e de secas durante $\mathrm{o}$ período correspondente (ex. Stahle e Cleaveland 1994; Dean 1994; Li et al. 2000; Hu et al. 2001; Stahle et al. 2007; Benson et al. 2007). Embora menos numerosos, também foram desenvolvidos estudos sobre a questão no Peru (Rein et al. 2004), nas regiões norte da Patagônia e central do Chile (Villalba 1994), e na região sul da Patagônia (Haberzettl et al. 2005). Essas investigações, além de identificarem a ocorrência do fenômeno MCA, evidenciaram também a influência do fenômeno El Niño, chamando a atenção para a complexidade do tema e necessidade de estudos regionais.

Investigações sobre adaptações culturais em resposta a estas condições climáticas anômalas, no entanto, são mais raras. Sob o aspecto específico da violência entre grupos pré-coloniais litorâneos, os trabalhos de Lambert (1997) e Raab e Larson (1997), associam um expressivo aumento de violência entre grupos da Califórnia durante o período entre 1150 e $1300 \mathrm{AD}$, em função do desequilíbrio no modo de subsistência baseado em recursos marinhos devido à elevação da temperatura do oceano ou devido a períodos prolongados de seca.

Apesar dos resultados de pesquisas que apontam para alterações climáticas em nível mundial durante os primeiros séculos do segundo milênio, alguns autores (ex. Bradley et al. 2008) advertem que a limitação dos dados sobre temperatura para o hemisfério sul durante este período deve ser considerada, embora admitam a ocorrência de anomalias hidrológicas em diversas partes do globo entre 900 e 1300 AD. Uma breve revisão dos trabalhos citados, por outro 
lado, revela que não existe sincronia entre os fenômenos regionais dentro do intervalo de tempo estimado para o Medieval Warm Period, o que reafirma a necessidade de estudos regionais.

\section{Considerações finais}

Não se pretendeu, com esta breve apresentação do fenômeno denominado Medieval Warm Period, associa-lo à aparente tendência de aumento da violência entre populações pescadorascoletoras pré-coloniais da costa sul do Brasil. Apenas, buscou-se chamar a atenção para um fenômeno que vem despertando o interesse de arqueólogos e paleoclimatologistas em todo o mundo, mas que ainda não foi investigado sob nenhum aspecto para o período pré-colonial no Brasil. O fato de os dados disponíveis para traumas violentos entre grupos pescadorescoletores ceramistas e não ceramistas fazerem convergir os episódios de violência para um intervalo de tempo ao redor do ano 1.000, mesmo período em que ocorre o MWP em várias partes do mundo, não deve ser desprezado, mas investigado, associando-se dados paleoclimáticos e arqueológicos em uma perspectiva regional. Por outro lado, enfatiza-se a existência de abundantes evidências históricas sobre significantes impactos sociais causados por alterações climáticas severas, tal como documentado, por exemplo, por Diaz e Stahle (2007), que apresentam os resultados de 12 estudos sobre impactos sociais diretos e indiretos em populações americanas durante os períodos pré-colonial e colonial.

Embora esta possa vir a constituir uma linha de pesquisa promissora para se compreender aspectos relacionados ao colapso do modo de vida sambaquieiro e subseqüente colonização do litoral por pescadores-coletores, entre eles a violência, enfatiza-se aqui que o alcance dos impactos sociais depende não apenas da intensidade e duração dos eventos climáticos, mas principalmente da forma de interação do homem com o meio, própria de cada tipo de organização social e econômica.

\section{Agradecimentos}

Ao professor Sidnei Linhares, responsável pelas coleções depositadas no Museu do Homem do Sambaqui, e ao professor Humberto Sobierajski, Secretário Geral do Colégio Catarinense, pelo interesse e apoio dado à pesquisa. Ao Dr. Luiz Roberto Godolfim, pelas radiografias da vértebra perfurada por ponta de projétil.

LESSA, A.; SCHERER, L.Z. The other side of the paradise: new data and reflections about violence among pre-colonial fisher-hunters. Revista do Museu de Arqueologia e Etnologia, São Paulo, 18: 89-100, 2008.

Abstract: The studies about acute traumas and violence among Brazilian precolonial coastal groups are rare. Difficulties due to taphonomic and methodological factors, besides the inexistence of iconographical data, are the main causes of the shortage of research on the theme. Given this scenario, the goal of this article is to contribute with new data about violence among southern fisher-hunters, which point to an increase of the aggression episodes when compared to the period of the coastal occupation by sambaqui builders. Finally, it is proposed the development of new approaches to understand this phenomenon, combining climatic events and specific socio-economic contexts.

Keywords: Acute trauma - Violence - Coastal population - Climatic events. 
O outro lado do paraíso: novos dados e reflexões sobre violência entre pescadores-coletores pré-coloniais. Revista do Museu de Arqueologia e Etnologia, São Paulo, 18: 89-100, 2008.

\section{Referências bibliográficas}

ANDRADE LIMA, T,

1999/2000Em busca dos frutos do mar: os pescadorescoletores do litoral centro-sul do Brasil. Revista USP, 44: 270-327.

BANDEIRA, D.R.

1992 Mudança na estratégia de subsistência do sítio arqueológico Enseada I - Um estudo de caso. Dissertação de Mestrado. Universidade Federal de Santa Catarina, Santa Catarina.

2004 Ceramistas pré-coloniais da Baia da Babitonga SC, Arqueologia e etnicidade. Tese de Doutorado. Departamento de História do Instituto de Filosofia e Ciências Humanas - UNICAMP, São Paulo.

BECK, A.M.

1972 A variação do conteúdo cultural dos sambaquis: litoral de Santa Catarina. Tese de Doutorado. Faculdade de Filosofia, Letras e Ciências Humanas, Universidade de São Paulo, São Paulo.

BENSON, L.; PETERSEN, K.; STEIN, J.

2007 Anasazi (pre-columbian native-american) migrations during the middle- $12^{\text {th }}$ and late $13^{\text {th }}$ centuries - Where they drought induced? Climatic Change, 83 (1-2): 187-213.

BRADLEY, S.; HUGHES, M.; DIAZ, H.

2008 Climate in Medieval Time. Science, 302: 404-405.

DEAN, J.

1994 The medieval warm period on the southern Colorado Plateau. Climatic Change, 26 (2-3): 225-241.

DIAZ, H.; STAHLE, D.

2007 Climate and cultural history in the Americas: an overwiew. Climatic Change, 83 (1-2): 1-8.

FIGUTI, L.

1993 O homem pré-histórico, o molusco e o sambaqui: considerações sobre a subsistência dos povos sambaquieiros. Revista do Museu de Arqueologia e Etnologia, São Paulo, 3: 67-80.

FIGUTI, L.; KLÖKLER, D.M.

1996 Resultados preliminares dos vestígios zooarqueológicos do Sambaqui Espinheiros II (Joinville, SC). Revista do Museu de Arqueologia e Etnologia, 6: 169-187.

FRY, D.

2005 The human potential for peace: An anthropological challenge to assumptions about war and violence. Oxford: Oxford University Press.
GASPAR, M.D.

1992 Aspectos da organização social de um grupo de pescadores, coletores e caçadores que ocupou o litoral do Estado do Rio de Janeiro. In: A.J.G. Araújo; L.F. Ferreira (Eds.) Paleopatologia e PaleoepidemiologiaEstudos multidisciplinares. Rio de Janeiro, Editora Fiocruz: 95-110.

1998 Considerations of the sambaquis of the Brazilian Coast. Antiquity, 72 (277): 592-615.

HABERZETTL, T.; FEY, M.; LÜCKE, A.; MAIDANA, N.; MAYR, C.; OHLENDORF, C.; SCHÄBITZ, F.; SCHLESER, G.; WILLE, M.; ZOLITSCHKA, B.

2005 Climatic induced lake level changes during the last two millennia as reflected in sedments of Laguna Potrok Aike, Southern Patagonia (Santa Cruz, Argentina). Journal of Paleolimnology, 33: 283-302.

HU, F.S.; ITO, E.; BROWN, T.; CURRY, B.; ENGSTROM, D.

2001 Pronounced climatic variations in Alaska during the last two millennia. Proceedings of the National Academy of Sciences of the United States of America, 98 (19): 10552-10556.

KEELEY, L.H.

1996 War before civilization. Oxford: Oxford University Press.

KITCHIN, I.; LANCASTER, E.

1948 Fatigue fracture of the ulna. The Journal of Bone and Joint Surgery, 30: 622-623.

KNEIP, L.M. (Org.)

1987 Coletores e pescadores pré-históricos de Guaratiba, RJ. Série Livros V. Rio de Janeiro: UFRJ.

1994 Cultura material e subsistência das populações pré-históricas de Saquarema, RJ. Documento de Trabalho, série arqueologia, $\mathrm{n}^{\circ} 2$. Rio de Janeiro: UFRJ.

LAMBERT, P.M.

1997 Patterns of Violence in Prehistoric Hunter-gatherer Societies of Coastal Southern California. In: D.L. Martin; D.W. Frayer (Eds.) Troubled Times: Violence and Warfare in the Past. Toronto, Gordon and Breach Publishers: 77-110.

LE BLANC, S.A.

2003 Constant Battles - Why we fight. New York: St. Martin's Griffin.

LESSA, A.

2004 Arqueologia da agressividade humana: a violência sob uma perspectiva 
paleoepidemiológica. História, Ciências, Saúde - Manguinhos, 11 (2): 279-296.

2005 Reflexões preliminares sobre paleoepidemiologia da violência em grupos ceramistas litorâneos: (I) Sítio Praia da Tapera - SC. Revista do Museu de Arqueologia e Etnologia, 15: 199-207.

LESSA, A.; MEDEIROS. J.

2001 Reflexões preliminares sobre a questão da violência em populações construtoras de sambaquis: análise dos sítios Arapuá (RJ) e Cabeçuda (SC). Revista do Museu de Arqueologia e Etnologia, 11: 77-93.

LESSA, A.; MENDONÇA DE SOUZA, S.M.F.

2004 Violence in the Atacama desert during the Tiwanaku period: social tension? International Journal of Osteoarchaeology, 14 (5): 374-388.

2006 Broken noses for the gods: ritual battles in the Atacama desert during the Tiwanaku period. Memórias do Instituto Oswald Cruz, 101 (supp.II): 133- 138.

LI, H.; BISCHOFF, J.; KU, T.; LUND, S.; STOTT, L. 2000 Climate variability in east-central California during past 1000 years reflected by highresolution geochemical and isotopic records from Owens Lake sediments. Quaternary Research, 54(2): 189-197.

LOVELL, N.

1997 Trauma analysis in Paleopathology. Yearbook of Physical Anthropology, 40: 139-70.

MARTIN, D.; FRAYER, D.

1997 Troubled Times: Violence and Warfare in the Past. Toronto: Gordon and Breach Publishers.

NEVES, W.

1984 Paleogenética dos grupos pré-históricos do litoral sul do Brasil (Paraná e Santa

OTTERBEIN, K. Catarina). Pesquisas, Série Antropologia, 43.

2004 How war began. Texas: Texas A\&M University Press.

ORAVA, S.; PURANEN, J.; ALA-KETOLA, L.

1978 Stress fractures caused by physical exercise. Acta Orthopaedica, 49 (1): 19-27.

PEARSON, M.P.; THORPE, I.J.N.

2005 Warfare, violence and slavery in prehistory. Oxford: BAR International Series 1374.

PROUS, A.

1992 Arqueologia Brasileira. Brasília: Editora UnB. PROUS, A.; PIAZZA, W.

1977 Documents pour la préhistoire du Brésil meridional. 2. L'état de Santa Catarina. Cahiers d'Archéologie d'Amérique du Sud, 4. Paris.
RAAB, M.; LARSON, D.

1997 Medieval climatic anomaly and punctuated cultural evolution in coastal southern California. American Antiquity, 62 (2): 319-336.

REIN, B.; LÜCKGE, A.; SIRICKO, F.

2004 A major Holocene ENSO anomaly during the Medieval period. Geophysical Research Letters, 31, L17211, doi:10.1029/ 2004 GL020161.

ROBB, J.

1997 Violence and gender in early Italy. In: Martin, D.L.; Frayer, D.W. (Orgs.) Troubled Times - Violence and Warfare in the past. Toronto: Gordon and Breach Publishers: 111-144.

RODRIGUES-CARVALHO, C.; LESSA, A.; MENDONÇA DE SOUZA, S.

(no prelo) Bioarchaeology of the sambaqui groups: skeletal morphology, physical stress and trauma. Bioarchaeology from the Midst of Shells. Lisboa: BAR International Series.

ROHR, A.

1966 Pesquisas Arqueológicas em Santa Catarina: I- Exploração sistemática do sítio da Praia da Tapera. Pesquisas, Série Antropologia, 15: 3-20.

SCHMITZ, P.I.

1996 Escavações arqueológicas do Pe. João Alfredo Rohr, S.J. - Visão de conjunto dos sítios da Tapera, Armação do Sul, Laranjeiras I e II, Pântano do Sul e Cabeçudas. Pesquisas, Série Antropologia, 53: 183-190.

SCHMITZ, P.I.; DE MASI, M.A.; VERARDI, I.; LAVINA, R.; JACOBUS, A.L.

1992 Escavações arqueológicas do Pe. João Alfredo Rohr, S.J. - O sítio arqueológico da Armação do Sul. Pesquisas, Série Antropologia, 48.

SCHMITZ, P.I.; VERARDI, I.; DE MASI, M.A.; ROGGE, J.H.; JACOBUS, A.L.

1993 Escavações arqueológicas do Pe. João Alfredo Rohr, S.J. - O sítio da Praia de Laranjeiras II. Uma aldeia da Tradição ceramista Itararé. Pesquisas, Série Antropologia, 49.

SILVA, S.B.; SCHMITZ, P.J.; ROGGE, J.H.; DE MASI, M.A.; JACOBUS, A.L.

1990 Escavações arqueológicas do Pe. João Alfredo Rohr, S.J. - O sítio arqueológico da Praia da Tapera: um assentamento Itararé e Tupiguarani. Pesquisas, Série Antropologia, 45. 
O outro lado do paraíso: novos dados e reflexões sobre violência entre pescadores-coletores pré-coloniais. Revista do Museu de Arqueologia e Etnologia, São Paulo, 18: 89-100, 2008.

STAHLE, D.; FYE, F.; COOK, E.; GRIFFIN, D.

2007 Tree-ring reconstructed megadroughts over North America since AD 1300. Climatic Change, $8 \mathrm{I} 3$ (1-2): 133-149.

STAHLE, D; CLEAVELAND, $\mathrm{M}$.

1994 Tree-ring reconstructed rainfall over the southeastern U.S.A. during the Medieval Warm Period and Litlle Ice Age. Climatic Change, 26 (2-3): 199-212.

TANABE, S; NAKAHIRA, J.; BANDO, E.; YAMAGUCHI, H.; MIYAMOTO, H.; YAMAMOTO, A.

1991 Fatigue fracture of the ulna occuring in pitchers of fast-pitch softball. The American Journal of Sports Medicine, 19: 317-321.

TENÓRIO, M.C.

1995 Estabilidade dos grupos litorâneos préhistóricos: uma questão para ser discutida. In: Beltrão, M. (Ed.) Arqueologia do Estado do Rio de Janeiro. Niterói, Arquivo Público do Estado do Rio de Janeiro: 43-50.
TIBURTIUS, G.; BIGARELLA, I.K.; BIGARELLA, J.J.

1950/51 Nota prévia sobre a jazida paleoetnográfica de Itacoara (Joinvile, Estado de Santa Catarina). Arquivos de Biologia e Tecnologia, V e VI: 315-366.

VILLALBA, R.

1994 Tree-ring and glacial evidence for the medieval warm epoch and the little ice age in southern South America. Climatic Change, 26 (2-3): 183-197.

WALKER, P.L.

1997 Wife Beating, Boxing, and Broken Noses: Skeletal Evidence for the Cultural Patterning of Violence. In: Martin, D.L.; Frayer, D.W. (Orgs.) Troubled Times - Violence and Warfare in the past. Toronto: Gordon and Breach Publishers: 145-180.

WRANGHAM, R.W; PETERSON, D.

1996 Demonic males: Apes and the origins of human violence. Boston: Houghton Mifflin. 